\title{
"So ist die Seele wie die Hand“ Rembrandts Aristoteles mit der Büste des Homer
}

Rembrandts Gemälde Aristoteles mit der Büste des Homer ermöglicht dem Betrachter eine Erfahrung großer Intimität (Abb. 5.1). Denn ohne dass wir zunächst wüssten, was hier eigentlich vorgeht, sind wir doch überzeugt, einen Moment von existenzieller Bedeutung zu beobachten. Der Philosoph steht vor einem dunklen Vorhang, seine Hand ruht auf dem Haupt einer Homer-Büste, die sich auf einem Tisch zur linken Seite befindet. Das heute im Metropolitan Museum of Art in New York aufbewahrte Bild misst 143,5 × 136,5 cm und weist damit ein nahezu quadratisches Format auf. Es zeigt die Figur annähernd lebensgroß. Das Gemälde ist signiert und auf das Jahr 1653 datiert.

Der Maler hat sich für eine strenge Begrenzung der künstlerischen Mittel entschieden. Schon die reduzierte Auswahl von Gegenständen zeugt davon. Das Gemälde wird durch eine von links oben nach rechts unten führende Diagonale bestimmt, die mit dem Lichteinfall korrespondiert. Dieser hebt das Gesicht des Aristoteles, seine rechte Hand und Teile seines Gewandes gegen das Dunkel des Hintergrundes ab. Zudem reflektieren Kettenglieder und ein Fingerring das Licht auf lebendige Weise.

Rembrandt verzichtet auf jede Buntheit. Braun-, Ocker-, Gold- und Weißtöne bilden einen zurückhaltenden Farbakkord. Im oberen Teil des Gemäldes gehen Körper, Haar und Kopfbedeckung unmerklich in den dunklen Hintergrund über. Dabei trägt Aristoteles ein prächtiges Gewand, das durch mehrlagige Stoffbahnen, die an den Ärmeln großzügig plissieren, den Reichtum seines Trägers kundtut. Sein Kopf wird von einem breitkrempigen Hut geschmückt, der mit einem golddurchwirkten Stoff unterfüttert ist.

Doch während die Körperhaltung und die Armstellung den Mann ebenso souverän wie elegant erscheinen lassen, wirkt das Antlitz melancholisch und ernst. Ein wenig verloren erscheint das Gesicht in der dunklen Fläche, als würde es schon bald von der Dunkelheit absorbiert. Der Philosoph hat seine rechte Hand auf den Kopf der marmornen Büste gelegt, während seine Linke auf Höhe der Hüfte Halt gefunden hat. Sein Blick führt an der Büste vorbei und

* Für Hinweise und Korrekturen danke ich Hartmut Böhme, Nils Büttner, Werner Busch, Paul Drogla, Sandra Kaden, Bertram Kaschek, Stefano Rinaldi und Bettina Uppenkamp. 


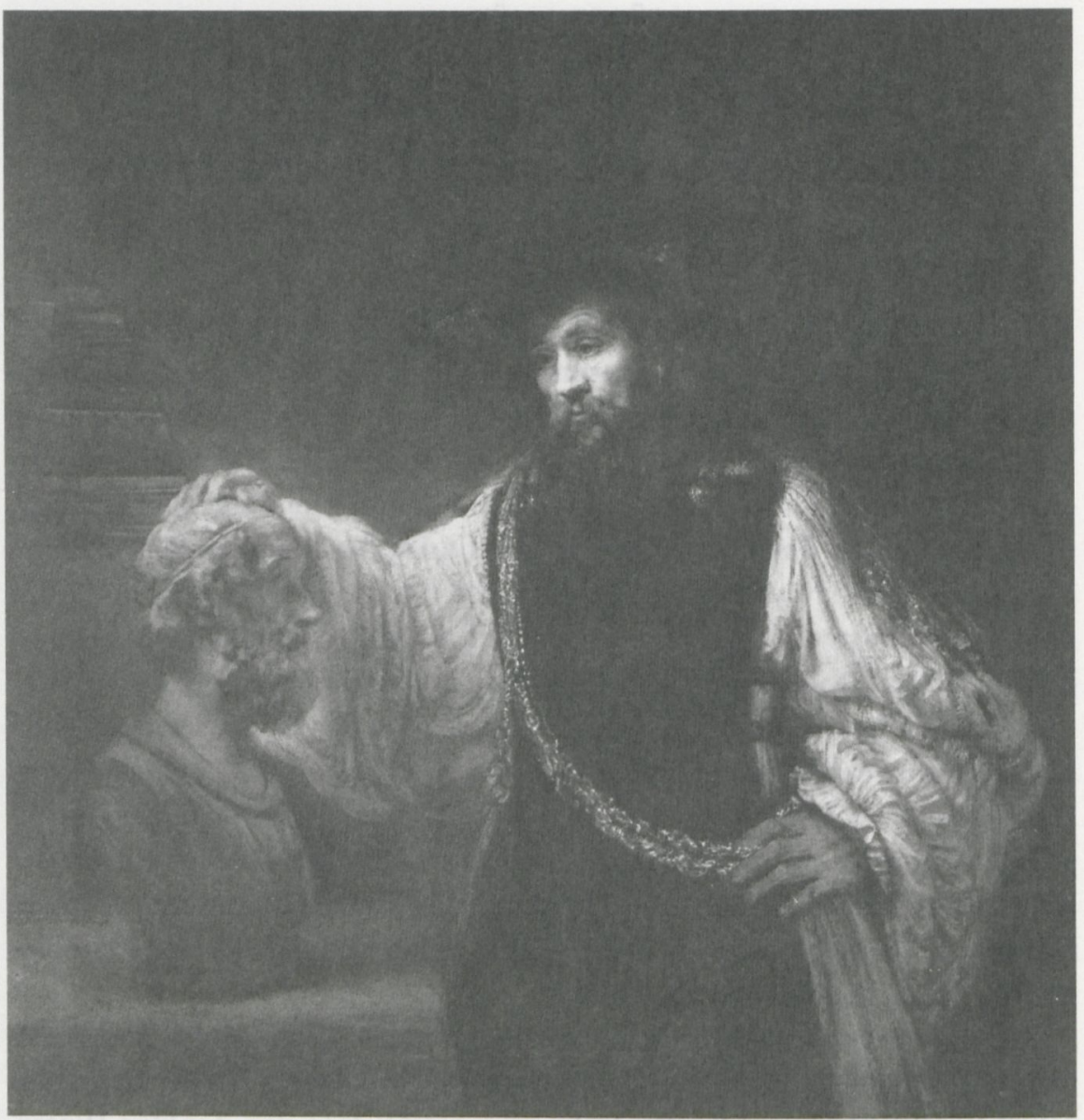

Abb. 5.1 Rembrandt, Aristoteles mit der Büste des Homer, 1653, Öl auf Leinwand, New York, The Metropolitan Museum of Art

verliert sich links der Bildgrenze. Er fokussiert keinen konkreten Gegenstand, sondern richtet sich vielmehr nach innen.

Dem ersten Anschein nach möchte Rembrandt den gesellschaftlichen Rang und das Selbstbewusstsein des Mannes betonen. Dieser trägt einen vollen Bart und sein vornehmes Obergewand ist aus schwarzem Samt. Am oberen Saum sind zwei Metallspangen angebracht, die den vorderen und hinteren Teil des Gewandes zusammenhalten. Eine goldene Ehrenkette reicht von seiner rechten Schulter zu seiner linken Hüfte, wo sie von zwei Fingern der dort befindlichen Hand berührt wird. Der kleine Finger der Linken ist leicht abgespreizt, und man nimmt am vorderen Glied einen schmalen goldenen Ring wahr, der auffällig durch den Widerschein des Lichts inszeniert wird. 
Links oberhalb des Büstenkopfes liegen mehrere Folianten, die übereinander gestapelt sind. Man erkennt die ledernen Einbände und bei manchen Büchern sogar eine metallene Schließe. Immer abwechselnd sehen wir den Rücken eines Folianten oder seinen Schnitt, so als wären die Bücher nach getaner Arbeit akkurat übereinander gestapelt worden. Ob es sich hier um Werke des Dichters oder des Philosophen oder gar beider handelt, ist freilich nicht zu entscheiden.

In der Forschung konnte der im Gemälde dargestellte Mann insofern als Aristoteles identifiziert werden, als sich an seiner goldenen Kette ein Medaillon befindet, das eine Profildarstellung Alexanders des Großen zeigt. Allerdings konnten für die genannte Medaille bisher kein konkretes Beispiel, sondern lediglich druckgraphische Vorbilder und ein Verrocchio zugeschriebenes Relief benannt werden. ${ }^{1}$ Der Philosoph war bekanntlich der Lehrer des makedonischen Königs, von dem wiederum überliefert wird, dass er ein Exemplar von Homers „Ilias" mit auf seine zahlreichen Feldzüge nahm. ${ }^{2}$ Darüber hinaus ist Homer jener Autor, auf dessen Werke der Philosoph in seinen Schriften allgemein, besonders aber in seiner „Poetik“ als Exemplum zurückgreift. Stimmt man der genannten Identifikation des Mannes als Aristoteles zu, kann es nicht verwundern, dass die Büste für den Betrachter im Profil zu erkennen ist und dem antiken Philosophen zugewandt erscheint, so als hielten beide ein stummes Zwiegespräch. Ein Zwiegespräch jedoch, das aus lauter Gegensätzen aufgebaut ist: Kunst hier, Philosophie dort. Stein hier, Fleisch dort. Mythos hier, Logos dort. Vergangenheit hier, Gegenwart dort. Zudem wird die Büste durch Rembrandts Lichtregie besonders inszeniert, denn im unteren Teil wird sie vom Licht wie von einer Aureole hinterfangen. Schließlich fällt auf, dass der Künstler in der Behandlung des Inkarnats von Aristoteles' Hand und der Oberfläche der Büste keinen Unterschied macht. ${ }^{3}$ Er betont also weder Härte noch Kälte des Marmors, sondern lässt diesen lebendig wie Fleisch erscheinen.

1 Vgl. Julius Samuel Held, „Aristoteles“, in: Ders.: Rembrandt-Studien, Leipzig 1983, S. 9-36, hier S. 18.

2 Vgl. dazu die sogenannte „Edition der Kassette“ Plutarch, Vies. Tome IX. Alexandre - César, übersetzt von Robert Flacelière und Émile Chambry, Paris 2003, 8, 2, und 26, 1; Plutarch, Moralia, mit englischer Übersetzung von Frank Cole Babbitt, Cambridge und London 1957, 327f-328a, 331d; Plinius, Histoire Naturelle, hg., übersetzt und kommentiert von Robert Schilling, Paris 2003 , S. 7 und 29.

3 Diese Beobachtung findet sich schon bei Svetlana Alpers, die die farbliche Parallele von Büste und rechter Hand beschreibt. Siehe Svetlana Alpers, Rembrandt als Unternehmer. Sein Atelier und der Markt, Köln 1989, S. 72. 
Über die Entstehungsumstände des Bildes sind wir relativ genau informiert. ${ }^{4}$ Der sizilianische Adelige und Sammler Don Antonio Ruffo gab das Gemälde bei Rembrandt in Auftrag, ohne dass damit der Wunsch nach einem bestimmten Thema einhergegangen zu sein scheint, worauf unlängst Paul Crenshaw hingewiesen hat. ${ }^{5}$ Dies wurde in der frühen Forschung anders beurteilt. Folgt man etwa Théodore Rousseau, erbat sich der sizilianische Adelige die Darstellung eines Philosophen und gewährte dem Niederländer einen gewissen gestalterischen Freiraum, dessen Wahl daraufhin auf den antiken Denker fiel. ${ }^{6}$ Christian Tümpel schließlich vermutete, dass der sizilianische Sammler über einen Mittelsmann eine historische Halbfigur bestellte. ${ }^{7}$ Für alle diese Hypothesen gibt es freilich keine Belege. ${ }^{8}$

Bei Ruffo haben wir es mit einem leidenschaftlichen Sammler und Kenner zu tun, der seinen Palast in Messina mit zahlreichen Werken bedeutender Künstler ausstattete und mit Malern jener Zeit in engem Kontakt stand. Das Gemälde dürfte 1653 in Auftrag gegeben worden sein, da es 1654 nachweislich in Messina eintraf. Zudem gefiel es dem italienischen Sammler so außerordentlich, dass er den Künstler brieflich um zwei weitere Werke bat, die heute mit den Gemälden des Homer und Alexanders in Verbindung gebracht werden. ${ }^{9}$ Doch konnte Rembrandt dem Wunsch Ruffos wegen seines Konkurses nicht sofort nachkommen, weshalb der Italiener zunächst seinen Landsmann

4 Immer wieder wird in der Forschung, so etwa bei Théodore Rousseau, Julius Samuel Held, Gary Schwartz oder Jeroen Giltaij, der sizilianische Kunstsammler Don Antonio Ruffo erwähnt, der das Gemälde bei Rembrandt, neben Alexander und Homer, als erstes von drei Werken in Auftrag gab. Vgl. Théodore Rousseau, „Aristotle contemplating the bust of Homer", in: The Metropolitan Museum of Art Bulletin, N.S. 20, 1961/62 (1962), S. 149-156, hier S. 15off.; Held 1983 (wie Anm. 1), S. 10; Gary Schwartz, Das Rembrandt-Buch. Leben und Werk eines Genies, übersetzt von Rosali und Saskia Bontes van Beek, München 2006, S. 218; Jeroen Giltaij, Ruffo en Rembrandt. Over een Siciliaanse verzamelaar in de zeventiende eeuw die drie schilderijen bij Rembrandt bestelde, Zutphen 1999, S. 43ff.

5 Vgl. Paul Crenshaw, Rembrandt's bankruptcy: The artist, his patrons, and the art market in seventeenth-century Netherlands, New York u.a.O. 2006, S. 125. Siehe auch Schwartz 2006 (wie Anm. 4), S. 218. Außerdem: Ders., Rembrandt. Sämtliche Gemälde in Farbe, Stuttgart 1987, S. 301.

6 Rousseau 1962 (wie Anm. 4), S. 152. Zur Überzeugung künstlerischer Eigenständigkeit siehe besonders Schwartz 2006 (wie Anm. 4), S. 218.

7 Vgl. Christian Tümpel, Rembrandt, Reinbek bei Hamburg 2006, S. 131.

8 Nils Büttner gibt allerdings zu bedenken, dass Rembrandt immerhin bekannt gewesen sein mag, dass Ruffo eine Galerie mit Gelehrtenporträts zusammenstellen wollte und dies die Wahl seines Themas beeinflusste. Vgl. Nils Büttner, Rembrandt. Licht und Schatten. Eine Biographie, Stuttgart 2014, S. 188-194, hier S. 192.

9 Zum neuesten Diskussionsstand vgl. Jonathan Bikker, „Kontemplation“, in: Ausst.-Kat. Der späte Rembrandt, hg. von Ders. und Gregor J.M. Weber, Rijksmuseum, Amsterdam, München 2014, S. 214-233, hier S. 217-227. 
Guercino bat, ein Gegenstück zum Aristoteles zu malen, das heute nicht mehr überliefert ist, von dem aber immerhin eine Vorzeichnung existiert. ${ }^{10}$

Die Antwort Guercinos auf den per Brief eingegangenen Auftrag Ruffos lässt darauf schließen, wie sehr der Sammler von Rembrandts Werk angetan war, denn der italienische Künstler nimmt das Lob des Auftraggebers auf und erwähnt nun seinerseits, dass ihm Rembrandts Radierungen bestens vertraut seien und dass er den Holländer „in aller Ehrlichkeit für einen großen Künstler" halte." Rembrandt erhielt für den Aristoteles 500 Gulden, was um ein Achtfaches über dem Betrag lag, den italienische Maler in der Regel für ihre Bilder erhielten. ${ }^{12}$ Wie aus den schriftlichen Quellen hervorgeht, erachtete der sizilianische Adelige das Gemälde gar als eines der wichtigsten seiner Sammlung. ${ }^{13}$

Mit der Erwähnung des Bildes in Ruffos Sammlungsinventar geht allerdings eine abweichende Größenangabe einher, wird hier doch eine Höhe von acht und eine Breite von sechs Palmi erwähnt, was einer heutigen Größe von $178 \times$ $134 \mathrm{~cm}$ entspräche. ${ }^{14}$ Das Gemälde wäre dann erheblich größer gewesen als die heutige Version, weshalb einige Wissenschaftler eine Beschneidung des Bildes für möglich gehalten haben..$^{15}$ Jo Kirby weist jedoch darauf hin, dass es sich bei den Palmi-Messungen lediglich um Annäherungswerte handelt, die einer ersten Orientierung dienten. Röntgenaufnahmen haben zudem zeigen können, dass das Gemälde das Originalformat aufweist. ${ }^{16}$

Aus alledem geht hervor, dass Ruffo seinen Auftrag an Rembrandt nicht mit einem bestimmten Thema versah, sondern schlicht ein Gemälde von der Hand des Meisters besitzen wollte. Als sicher kann gelten, dass der Holländer keinesfalls vorhersehen konnte, dass es zu weiteren Aufträgen kommen würde. Im Gegenteil schuf er den Aristoteles im Bewusstsein eines Einzelwerkes, welches für sich sprechen sollte. So sollen im Folgenden auch keine Hypothesen darüber angestellt werden, inwiefern die zusätzlich bestellten Bilder das

10 Siehe dazu Jakob Rosenberg, „Rembrandt and Guercino“, in: The Art Quarterly, Jg. 7, 1944, Nr. 2, S. 129-134, hier S. 131ff.

11 Christian Tümpel, Mythos und Methode, Antwerpen 1986, S. 361-364, hier S. 361. Siehe zur Bewunderung Guercinos gegenüber Rembrandt auch Rosenberg 1944 (wie Anm. 10), besonders S. 130.

12 Vgl. Held 1983 (wie Anm. 1), S. 10.

13 Vgl. Rousseau 1962 (wie Anm. 4), S. 154.

14 Vgl. Giltaij 1999 (wie Anm. 4), S. 44.

15 Vgl. Held 1983 (wie Anm. 1), S. 14; Rosenberg 1944 (wie Anm. 10), S. 131; Schwartz 2006 (wie Anm. 4), S. 221.

16 Vgl. Jo Kirby, „A note on the seventeenth-century ,palmo in the context of Don Antonio Ruffo's collection“, in: The Burlington Magazine, Jg. 134, 1992, Nr. 1070, S. 297-298, besonders S. 298. 
Bildprogramm vervollständigt hätten, sondern lediglich der Aristoteles interpretiert werden.

Grundlegend für die Forschung war ein Aufsatz von Herbert von Einem aus dem Jahre $1952 .{ }^{17}$ Schon von Einem verwies auf die anderen Homerdarstellungen Rembrandts und deutet das Bild grundsätzlich als ein Zwiegespräch zwischen Dichter und Denker, als eine Begegnung „im Medium des Lichts“.18 Zudem erwähnt er die Tatsache, dass die Gipsbüsten von Homer und Aristoteles im Versteigerungsinventar unmittelbar nacheinander genannt sind und nebeneinander gestanden haben müssen. ${ }^{19}$ Darüber hinaus macht er im $\mathrm{Zu}$ sammenhang mit der goldenen Kette auf die „catena aurea Homeri“ aufmerksam - ein mystisches Sinnbild des Zusammenhangs alles Seienden. Schließlich verweist er auf die positive Homerrezeption im Holland des 17. Jahrhunderts. Laut von Einem ist Homer für Rembrandt ein Poeta vates, also der Inbegriff des göttlich inspirierten Sehers. In ikonographischer Hinsicht greife der Künstler auf die Tradition des Sammlerbildnisses zurück, wofür von Einem zahlreiche Beispiele gibt. ${ }^{20}$ Der Maler stelle in seinem Gemälde Dichtung und Philosophie als zwei Formen derselben Wahrheit dar, wie es auch im Mittelalter üblich gewesen sei. Er suche nicht das Trennende von Raum und Zeit, sondern das überhistorisch Verbindende menschlichen Wesens. ${ }^{21}$ Dafür bediene er sich stiller Gebärden und des Blicks nach Innen.

In seinem Aufsatz aus dem Jahre 1969 deutet auch Julius Samuel Held das Bild auf mehreren Ebenen. Zunächst im Sinne der Temperamentenlehre als Ausdruck der Melancholie, die für bedeutende Denker charakteristisch sei,

Herbert von Einem, „Rembrandt und Homer“, in: Wallraf-Richartz-Jahrbuch, Jg. 14, 1952, S. 182-205, hier S. 187.

18 Ebd., S. 195.

19 Vgl. ebd., S. 187 f.

20 Im Anschluss an von Einem hat Christian Tümpel allgemein auf den Altersstil des Künstlers verwiesen und der damit einhergehenden Sensibilität für Gebrechlichkeit und Schwäche des alternden Menschen, der stärker nach innen als nach außen schaut. Siehe Tümpel 2006 (wie Anm. 7), S. 134. Horst Gerson äußerte sich ablehnend zum Aristoteles und tadelte das vermeintlich priesterliche Gewand des Philosophen, das ihn an phantastische Trachten des 16. Jahrhunderts erinnere, wo es doch im Rahmen der Darstellung eines Naturwissenschaftlers und Systematikers darum gegangen wäre, die taghelle Klarheit eines Vermeer anzustreben. Vgl. Horst Gerson, Rembrandt. Gemälde. Gesamtwerk, Amsterdam 1968, S. 114-116. Bob Haak hat es lediglich bei einer genauen Schilderung der Auftrags- und Vertragsumstände belassen. Vgl. Bob Haak, Rembrandt. Leben und Werk, Köln 1976, S. 240-241. Christopher Wright bezieht sich auf Held, wenn er im Jahr 2000 ebenfalls den melancholischen Charakter des Aristoteles innerhalb der knappen Bildanalyse seiner Rembrandt-Monographie herausstellt. Vgl. Christopher Wright, Rembrandt, München 2000, S. 70. Vgl. von Einem 1952 (wie Anm. 17), S. 190. 
worauf der antike Philosoph in seinen "Problemata“ selbst hingewiesen habe. ${ }^{22}$ Allerdings wissen wir, dass es sich dabei um eine pseudoaristotelische Schrift handelt. ${ }^{23}$ Sein wesentliches Argument zieht Held aus der Farbgebung des Gemäldes, denn die das Bild dominierende Farbe Schwarz, so etwa auf dem Gewand des Aristoteles, sei für Melancholiker ebenso typisch wie das tiefsinnige Nachdenken, wenn nicht gar verzweifelte Brüten. ${ }^{24}$ Sodann greift er von Einems Hinweis auf den Typus des Sammler- und Gelehrtenbildnisses auf, wofür er in geradezu inflationärer Weise Belege gibt. ${ }^{25} \mathrm{Im}$ Kontext seiner Melancholiethese verweist Held zusätzlich auf das Moment der Vanitas, was er wiederum mit Porträts belegt, die Humanisten statt mit einer Büste mit einem Totenschädel darstellen. ${ }^{26}$

Folgt man seiner Deutung, wird Aristoteles für Rembrandt zu einer Art Identifikationsfigur, muss der Philosoph doch schmerzlich erkennen, dass die durch Homer versinnbildlichte Kunst höher als der durch die Kette repräsentierte Reichtum und die Anerkennung der Mächtigen zu bewerten sei. Dafür habe sich Rembrandt der unterschiedlichen Inszenierung beider Hände bedient. Während die rechte Hand leicht und hell auf dem Kopf des antiken Dichters ruhe, sei die linke verschattet und erscheine schwer.

Im Unterschied zu Held hat sich Margaret Deutsch Carroll in ihrer Deutung auf die Nachdenklichkeit des Aristoteles konzentriert. ${ }^{27}$ So befinde sich Aristoteles in der Denkbewegung vom sinnlichen Betrachten zu intellektueller Schau. ${ }^{28}$ Darüber hinaus glaubt sie entdecken zu können, dass sich der Philosoph mit der Frage menschlicher Werte auseinandersetze. ${ }^{29}$ Wichtig ist zudem ihr Hinweis auf die Vorstellung vom Schaffen eines Kunstwerkes als philosophische Tätigkeit, wie sie von Zeitgenossen Rembrandts vertreten wurde. Schon Aristoteles erwähne in seiner "Metaphysik“ die Funktion von Skulpturen, deren Betrachtung zur Interaktion zwischen Ursache und Wirkung führen könnte, während er in seiner „Poetik“ den philosophisch-kontemplativen Wert

Vgl. Held 1983 (wie Anm. 1), S. 26. Zum Komplex der Melancholie und Aristoteles vgl. Raymond Klibansky, Erwin Panofsky und Fritz Saxl, Saturn und Melancholie. Studien zur Geschichte der Naturphilosophie und Medizin, der Religion und der Kunst, übersetzt von Christa Buschendorf, 2. Aufl., Frankfurt am Main 1990, S. 55-91. Vgl. Held 1983 (wie Anm. 1), S. $5^{8 .}$

24 Vgl. ebd., S. 27.

25 Vgl. ebd., S. 27-28.

26 Vgl. ebd., S. 24-25.

27 Dabei favorisiert Carroll sehr allgemeine Theoreme, worunter der konkrete Bezug zum Gemälde leidet. Vgl. Margaret Deutsch Carroll, „Rembrandt's Aristotle: exemplary beholder", in: Artibus et historiae, Jg. 5, 1984, Nr. 10, S. 35-56. Vgl. ebd., S. $35-38$. 
von Kunstwerken schätzt. Die höchste Form menschlicher Aktivität stelle in diesem Zusammenhang die Kontemplation dar, wie es in der "Nikomachischen Ethik" heißt. ${ }^{30}$

Eine Kritik der bestehenden Interpretationen verdanken wir Paul Crenshaw insofern, als er darauf hinweist, dass es sich bei dem dargestellten Mann nicht zwingend um Aristoteles handeln müsse, sondern vielmehr Apelles, der Hofmaler Alexanders des Großen, gemeint sei. Crenshaw liefert zahlreiche Belege für die Bedeutung des antiken Künstlers in der Kunsttheorie des 17. Jahrhunderts, sodass es seines Erachtens näherliegend ist, den schwarz gekleideten Mann als Apelles und nicht als Aristoteles zu identifizieren. ${ }^{31}$ Demgegenüber hat Walter Liedtke in seinem Aufsatz zum Aristoteles an der Identifikation des griechischen Philosophen festgehalten und die These geäußert, es sei die inszenierte Sinne-Ikonographie von Tasten und Sehen gewesen, die eine erste Identifikation des dargestellten Mannes als Aristoteles oder Albertus Magnus im Sammlungsinventar von Ruffo möglich gemacht habe. Gegen Crenshaw betont er zudem die Unterschiede zwischen Rembrandts Gemälde und der Apelles-Ikonographie, werde der Hofkünstler Alexanders doch in allen Varianten jung dargestellt und nie in einem vergleichbaren Kontext präsentiert, wie er für den Aristoteles geltend zu machen ist. Schließlich verweist Liedtke auf die Tradition des Paragone und die Überlegenheit, die man glaubte im Anschluss an den griechischen Philosophen dem Sehsinn zuweisen zu dürfen. So lautet das Fazit seiner Überlegungen: „Rembrandt's appreciation of Aristotle probably focused on questions of observation, and with respect to painting must have been influenced by the philosopher's opinions of the senses as cited in the ongoing paragone debate."32 Zuletzt ist das Bild von Jonathan Bikker im Kontext einer Ausstellung zum späten Rembrandt wieder im Sinne Helds als Ausdruck kreativer Melancholie gedeutet worden, ohne dass in Bezug auf die Interpretation des Gemäldes neue Erkenntnisse erzielt worden wären. ${ }^{33}$

Liedtke erwähnt allerdings nicht, dass schon Svetlana Alpers den Tastsinn im Aristoteles-Gemälde als bestimmendes Bildthema erkannt hatte. ${ }^{34}$ Alpers zufolge reize der Leidener Künstler den Tastsinn des Betrachters aufgrund des pastosen Farbauftrags, der besonders für sein Spätwerk charakteristisch sei. ${ }^{35}$

Vgl. ebd., S. 48.

Vgl. Crenshaw 2006 (wie Anm. 5), S. $148 \mathrm{ff}$.

Walter Liedtke, „The meaning of Rembrandt's Aristotle with a Bust of Homer“, in: Volker Manuth und Axel Krüger (Hg.), Collected opinions: essays on Netherlandish art in honour of Alfred Bader, London 2004, S. 72-87, hier S. 80. 
Schlussfolgernd heißt es: „Rembrandt stellt den Tastsinn als die Verkörperung des Gesichtssinns dar: Sehen mit Händen“. ${ }^{36}$ Das unterstellte Bedürfnis des Betrachters, die Werke berühren zu wollen, wird somit zur Clavis interpretandi für das Rembrandtsche CEuvre erklärt. Problematisch ist dies insofern, als der Künstler in seinen wenigen schriftlich überlieferten Äußerungen fordert, seine Bilder seien aus einem gewissen Abstand zu betrachten, wodurch die Wahrnehmung des pastosen Farbauftrags erheblich zurückgenommen wird. ${ }^{37}$

Wenn im Folgenden eine neue Interpretation des Bildes angestrebt wird, so soll es erstens darum gehen, die literarische Quelle zu benennen, die es uns erlaubt, in dem bärtigen Mann Aristoteles zu entdecken. Zweitens muss der dargestellte Moment präziser in Hinsicht auf die Bilderzählung bestimmt werden. Drittens sei schließlich in Anlehnung an Liedtke der programmatische Charakter des Bildes im Sinne impliziter Kunsttheorie herausgearbeitet.

\section{1. „Anagnorisis und Peripetie“}

Zunächst zur Schriftquelle. Crenshaw muss bei seiner Identifikation des Mannes als Apelles entschieden widersprochen werden, weil eine Quelle existiert, die über das Äußere des Philosophen Aristoteles Auskunft gibt. Nimmt man noch einmal seine vornehme Kleidung und den auffällig inszenierten Ring am kleinen Finger zur Kenntnis, kann man an jenen Passus aus Diogenes Laertius' "Leben und Meinungen berühmter Philosophen" denken, wo es über den Starigiten heißt: „auch war er [Aristoteles, J.M.] schwach auf den Beinen, wie man sagt, und kleinäugig, kleidete sich aber stattlich und ließ es an Fingerringen und Haarpflege nicht fehlen. ${ }^{38}$ Offensichtlich nimmt Rembrandt auf diese Beschreibung Bezug, wenn er elegante Kleidung, Haare und Bart, vor allem aber den gleißenden Goldring auffällig in Szene setzt. Eine solche literarische Beschreibung, wie sie auf das Äußere von Rembrandts Mann in Schwarz zutrifft, existiert meines Wissens für Apelles nicht. So verweist Crenshaw zwar

Ebd., S. 72 .

37 Dies mindert jedoch nicht die Faszination des Leideners für die Berührung mit der Hand als Form der aktiven Wahrnehmung der Welt, weshalb er jenes Motiv oft in seinen Arbeiten integriert, so etwa auch im Kontext der Blindheit. Hierin folge ich Alpers, die die relevanten Quellen nennt; vgl. ebd., S. 70-72.

38 Diogenes Laertius, Leben und Meinungen berühmter Philosophen, übersetzt von Otto Apelt, 3. Aufl., Hamburg 199o, V,1. Eine holländische Übersetzung des antiken Textes erschien jedoch erst 1655, also zwei Jahre nach Entstehung des Gemäldes unter dem Titel: „Kort begrijp van Diogenes Laertius, zijnde het leven heerlijke Spreuken, loffelijke Dagen en snedige Antwoorden der oude philosophen, waar bijkomen eenige treffelijke Spreuken en Gelijkenissen uyt verscheyden heydensche en andere schrijvers" in Rotterdam. 
allgemein auf die reichhaltige Apelles-Ikonographie, kann aber kein einziges Bild benennen, auf das sich Rembrandt hätte beziehen können.

Bei weitem erstaunlicher ist jedoch Rembrandts Wahl des Themas. Mag die gedankliche Verbindung von Aristoteles und Homer auch naheliegen, ist die bildliche Verknüpfung in dieser Form ohne Präzedenz. Einen ersten, aber vagen Ausgangspunkt bildet der Auftraggeber. Rembrandt wird seinen Auftrag mit einem gewissen Ehrgeiz durchgeführt haben, nicht nur der guten Bezahlung wegen, sondern auch weil er es mit einem ambitionierten Sammler zu tun hatte, dessen kennerschaftliches Urteil nach einem ebenso originellen wie anspruchsvollen Thema verlangte.

Die Frage, warum Rembrandt in seinem Gemälde eine Homer-Büste dargestellt hat, scheint in diesem Zusammenhang noch am einfachsten zu beantworten zu sein. Wiederum war es Held, der darauf hinwies, dass der Schöpfer von "Ilias" und „Odyssee" im 17. Jahrhundert nicht unangefochten war, sondern in den Niederlanden als Sinnbild einer antiklassischen Gesinnung erachtet werden konnte. So lautete in jener Zeit die Frage, ob man Vergil oder Homer den Vorzug zu geben habe. Vergil repräsentierte im Unterschied zu Homer den Klassizismus. Er war der Hofpoet des Augustus und das Idol klassizistischer Theorie. Dass dieser Klassizismus um die Mitte des 17. Jahrhunderts tonangebend wurde, belegt etwa Joost van den Vondels 1646 auf Niederländisch erschienene Einführung in das Werk Vergils. Auch Julius Caesar Scaliger wetterte in seiner „Poetik“ schon in der zweiten Hälfte des 16. Jahrhunderts gegen Homer, dessen Epen er rundheraus ihrer lächerlichen Phantastik wegen ablehnte. ${ }^{39}$ Vor allem ein vermeintlich vulgärer Darstellungsstil und sein platter Naturalismus riefen Kritiker auf den Plan. Im Zentrum der Debatte stand der Decorumverstoß des griechischen Dichters - eine Anfeindung, der sich auch Rembrandt ausgesetzt sah. ${ }^{40}$ So scheint es kein Zufall zu sein, dass Rembrandt am unteren Ende der Büste seine Signatur anbrachte, womit er eine Identifikation mit dem Dichter zum Ausdruck bringt.

Vgl. Julius Caesar Scaliger, Poetices libri septem/ Poetice, Bd. 4, 5. Buch, 3. Kap., hg., übersetzt, eingeleitet und erläutert von Gregor Vogt-Spira, Stuttgart 1987. Im 3. Kapitel wählt Scaliger immer wieder Formulierungen, die Vergil auf- und Homer abwerten, so etwa beim Vergleich von "Odyssee ${ }^{4}$ und ${ }_{n}$ Aeneis“, wenn es heißt: „Nirgendwo aber, wo Zeitabschnitte, Tag, Nacht beschrieben werden, verdient es Homer, mit Vergil verglichen zu werden. Nicht nur, wo er selbst aus eigenem spricht, macht er nämlich Göttliches aus Niedrigem“. Ebd., 5. Buch, 3. Kap., S. 133 .

40 Zur Debatte um Homer und Vergil vgl. Reinhard Brandt, „Rembrandt. Aristoteles und die Büste Homers“, in: Ders., Philosophie in Bildern. Von Giorgione bis Magritte, 2. Aufl., Köln 2001, S. 217-225, hier S. 218-221. 
Die Idee, die beiden antiken Geistesgrößen bildlich zu vereinen, sieht von Einem in erster Linie in Rembrandts Kunstkammer begründet, da beide Büsten in der Sammlung des Künstlers nebeneinander gestanden haben. Zudem werden Rembrandt die historischen Relationen zwischen Homer, Aristoteles und Alexander bekannt gewesen sein. Folgt man von Einem, soll Rembrandt auf mittelalterliche Aristoteles-Darstellungen zurückgegriffen haben, so etwa von dem um 1470 tätigen Justus van Ghent, der eine enge Verbindung zu Italien besaß. ${ }^{41}$ Auch mit der Geste des Handauflegens folge er der Tradition und dem gängigen Motiv des Sammlerbildes. ${ }^{42}$ Zudem hat von Einem auf den hellenistischen Blindentypus hingewiesen, der in der Homer-Büste aufgegriffen wird. ${ }^{43}$ Doch alle diese Hinweise reichen nicht aus, um Themenwahl und formale Gestaltung zu erklären. Rembrandt nutzt weder ein antikes Kostüm noch greift er für das Antlitz des Philosophen auf eigene Porträtstudien zurück, wie Held festgestellt hat. ${ }^{44}$

Dass der Künstler im Streit um den Vorrang von Vergil und Homer nicht unentschieden blieb, belegt seine Stammbuchzeichnung für Jan Six aus dem Jahre 1652. Für seine Federzeichnung (Abb. 5.2) isoliert der Künstler eine Gruppe aus Raffaels Parnass, die den blinden Dichter unter seinen aufmerksamen Zuhörern zeigt. Wie bei einer Johannespredigt hat Rembrandt Männer und Frauen, Alte und Junge zusammengeführt, um die universale Botschaft von Homers Dichtung anzuzeigen. Der Poet hat die rechte Hand erhoben, als würde er nach Worten suchen und als könne er seine Erzählung ertasten, während alle dargestellten Personen gebannt lauschen oder seine Worte mitschreiben. Zudem hat Rembrandt seinen Bildausschnitt so gewählt, dass der blinde Dichter auf der vertikalen Achse des Bildes platziert ist und sein Haupt alle anderen überragt, steht er doch auf der Spitze eines leicht ansteigenden Hügels. In diesem Zusammenhang muss der für den Betrachter offene Halbkreis erwähnt werden, den wir imaginär betreten können, um zu den Hörern hinzuzutreten. Und obwohl es sich um eine schnell durchgeführte Zeichnung zu handeln scheint, meint man die leeren Augen des blinden Dichters erkennen zu können. Nicht ohne eine gewisse Ironie ist im Zusammenhang des Streits um den Vorrang von Homer und Vergil jedoch, dass Raffael, der Theoretikern wie Franciscus Junius als Exemplum einer an antik-klassischen Idealen orientierten Malerei galt, hier als Kronzeuge für die Wertschätzung Homers berufen wird.

41 Vgl. von Einem 1952 (wie Anm. 17), S. $188 \mathrm{f}$.

42 Vgl. ebd., S. 19off. Siehe dazu auch die von von Einem aufgezeigten Beispiele.

43 Vgl. ebd., S. 184.

44 Vgl. Held 1983 (Anm. 1), S. 16. 


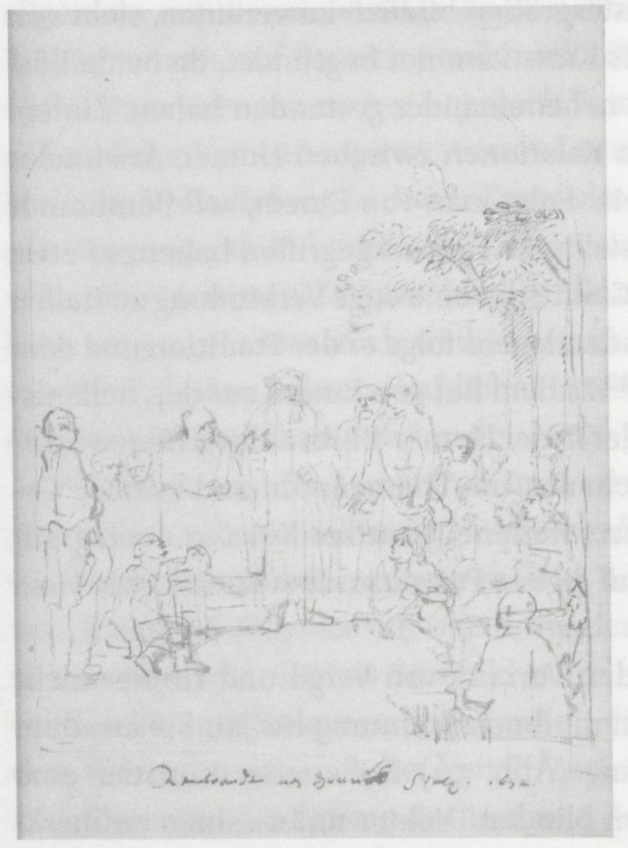

Abb. 5.2

Rembrandt, Homer trägt Dichtung vor, 1652, Federzeichnung, Amsterdam, Sammlung Six (Inv.-Nr. B. 913)

Im Zusammenhang mit Rembrandts Antiklassizismus sei an dessen Satire auf die Kunstkritik (Abb. 5.3) erinnert, die von Jan Emmens als polemische Auseinandersetzung mit Junius gedeutet wurde. ${ }^{45}$ Der drastische Decorumverstoß des vorn rechts dargestellten "scheißenden“ Künstlers mag in diesem Zusammenhang als beredtes Zeugnis von Rembrandts antiklassischer Kunsttheorie verstanden werden. Wichtig ist die ironische Argumentation des Blattes, denn schon hier bezieht sich Rembrandt in einzelnen Teilen auf die ParnassDarstellung Raffaels, der er bestimmte Figuren entnimmt, um die Klassizisten ihrer eigenen Blindheit zu überführen. Nicht Raffael, sondern eine dogmatische, in ihren Regeln erstarrte Kunstkritik wird hier verspottet. ${ }^{46}$ So wird erkennbar, dass Rembrandt mit der Abbildung der Büste Homers im Gemälde eindeutig Partei für den antiklassischen Dichter nimmt. Viele dieser Hinweise und Vergleiche sind in der Forschung seit langem bekannt. Doch wie kann eine weiterführende Deutung des Aristoteles-Gemäldes aussehen?

Meine Beschreibung hat nahezu alle Gegenstände des Bildes erfasst und die elementaren Gestaltungsmittel benannt, aber wie steht es um seinen

45 Vgl. Jan A. Emmens, Rembrandt en de regels van de kunst, Utrecht 1968, S. 150-154.

46 Vgl. Jürgen Müller, Der sokratische Künstler. Studien zu Rembrandts Nachtwache, Leiden 2015, S. 8f. Rembrandt bediente sich häufig italienischer Zitate im Sinn eines vollzogenen Antiklassizismus, so etwa in der Blendung des Simson oder der Judenbraut. 
Abb. $5 \cdot 3$

Rembrandt, Satire auf die Kunstkritik, 1644, Federzeichnung, New York, The Metropolitan Museum of Art

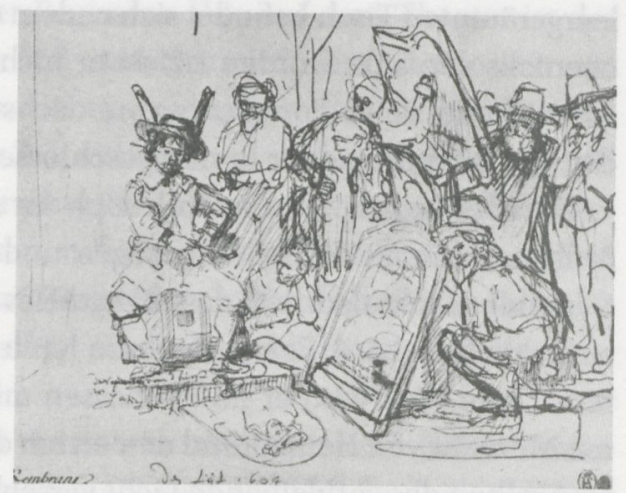

eigentlichen Inhalt? Um über die bestehende Forschung hinauszugelangen, müssen wir uns erneut der Bilderzählung zuwenden. Für Held war das Moment der Vanitas zentral. So als würde Aristoteles über die Frage der Vergänglichkeit des Ruhms nachdenken, als würde er bezweifeln, dass seine Fama wie jene Homers die Zeiten überdauern wird. Diese Deutung sei zurückgewiesen, um in Bezug auf die Bilderzählung und ihren Protagonisten im Folgenden eine stärker biographische Deutung zu vertreten. So berichtet Diogenes Laertius in seiner Lebensbeschreibung, dass sich Aristoteles nach dem Tode Alexanders wegen seiner großen Nähe zum makedonischen Königshaus und der damit zusammenhängenden Anklage der Gotteslästerung gezwungen sah, Athen, die Akademie und seine Familie zu verlassen, um seiner Verurteilung zum Tode durch eine heimliche Flucht nach Chalkis zu entgehen. ${ }^{47}$ Dort sei er wenig später gestorben. Dieser existenzielle Kontext ist für das Gemälde maßgebend.

Im Unterschied zur bestehenden Sekundärliteratur gehe ich davon aus, dass es sich bei der dargestellten Szene präzise um den Moment von Aufbruch und Abschied handelt: Aristoteles ist soeben von seinem Stuhl aufgestanden, dessen Rückenlehne man an der rechten Bildgrenze entdecken kann. Er hat die herumliegenden Bücher verschlossen und ordentlich aufgestapelt. Auf dem

Vgl. Ingemar Döring, Aristotle in the Ancient Biographical Tradition, Göteburg 1957, besonders S. 344-348. In den von Döring angegebenen Quellen finden sich über den Tod des Philosophen unterschiedliche Angaben. Dass Aristoteles auf Chalkis starb, berichtet zum Beispiel Strabo (Geo, X,1,11); dass er ca. ein Jahr nach Alexander starb, liest man bei Aulus Gellius (Noct. att. XVII 21, 25 und 34); dass er an einer Krankheit (nosos) starb, berichten z.B. Diogenes Laertios (wie Anm. 38, V, 9) und Dionysios von Halikarnass (Ep. ad Ammaeum 5, S. 727). Von Eumulus (in Laertios 1990 (wie Anm. 38, V, 6)) stammt die an die Sokratesvita angelehnte Vorstellung, dass sich der Philosoph auf Chalkis mit Akonit ums Leben brachte. Plutarch hingegen schweigt sich in seiner Alexandersvita über den Tod des Aristoteles ganz aus. 
leergeräumten Tisch befindet sich zudem ein Futteral für ein Schreibgerät, das ebenfalls verpackt worden ist, da er nichts mehr aufschreiben wird. ${ }^{48}$ Seine Arbeit findet keine Fortsetzung am nächsten Tag, sondern ist endgültig beendet. Die Bücher sind für immer geschlossen.

Darüber hinaus hat der Philosoph für seinen unmittelbar bevorstehenden Aufbruch seinen Mantel angezogen und einen Hut aufgesetzt. Rembrandts Gemälde macht deutlich, dass Aristoteles nicht mehr an seine Wirkungsstätte zurückkehren wird. Er berührt zum letzten Mal den Kopf des geliebten Dichters. Diese Welt wird er nun verlassen müssen. Es handelt sich um den letzten Moment von Heimat und den ersten der Verbannung. Schon bald wird die Dunkelheit das verbleibende Licht verschlungen haben.

Dies alles weiß der Künstler in einem einzigen Moment zu verdichten. In diesem Zusammenhang sei ausdrücklich die ästhetische Wirkung des annähernd quadratischen Bildformats betont. Mit seinen vier gleich langen Seiten und vier rechten Winkeln ist das Quadrat eine stabile Form, die alle Bewegung und jedes Richtungsstreben einschränkt. Es lässt den tragischen Moment gedehnt erscheinen. Für diesen Augenblick steht die Zeit im Gemälde still. Einer solchen Bild- und Zeitkonstruktion bedient sich Rembrandt ebenfalls in seiner Darstellung der Bathseba, die den verhängnisvollen Brief König Davids liest. Auch hier kommt dem quadratischen Format eine ähnliche Funktion zu. Es dehnt den Zeitpunkt ins Unerträgliche, jenen Moment, in dem die junge Frau erkennen muss, dass mit dem Brief Davids der Tod ihres Mannes besiegelt ist.

Trifft meine Beschreibung zu, so handelt es sich bei der im Gemälde dargestellten Szene um die tragische Selbsterkenntnis des Helden, die von Aristoteles so genannte Anagnorisis, mit der ein "Umschlag von Unkenntnis in Kenntnis“ einhergeht, wie es in dessen „Poetik“ "heißt. ${ }^{49}$ Zudem entspricht der Künstler in seinem Gemälde insofern den Forderungen des antiken Philosophen, als Anagnorisis dann am effektivsten zur Geltung kommt, wenn sie mit der Peripetie, der tragischen Wendung des Dramas, einhergeht. ${ }^{50}$ Aristoteles geht nicht nur in die Verbannung, sondern auch seinem baldigen Tod entgegen.

48 Giltaij hat darauf aufmerksam gemacht, dass schon Held das Detail als mögliches Schreibbehältnis identifiziert hat. Vgl. Giltaij 1999 (wie Anm. 4), S. 49. Siehe auch Julius Samuel

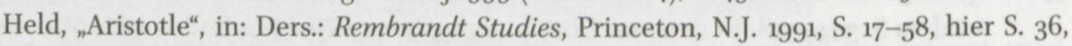
Anm. 71. (In der deutschen Ausgabe wird diese Information nicht übernommen.).

49 Aristoteles, Poetik, Griechisch/Deutsch, übersetzt und hg. von Manfred Fuhrmann, Stuttgart 1982, Kap. 11, 1452a-b.

Zu Peripetie und Anagnorisis vgl. ebd., 1452auff. und 1452a22-29. Zur Vergleichbarkeit von Rembrandt's Bilddramaturgie mit der peripeteia-Rezeption in der zeitgenössischen Theatertheorie siehe Jan-Erik Sluijter, „Rembrandt's portrayal of the passions and Vondel's 'staetveranderinge'، , in: Netherlands Yearbook for History of Art, Bd. 60, 2010, Nr. 1, S. 285-305. 
Rembrandt erweist sich als kluger Regisseur. Wie auf dem Theater ist der Vorhang im Bild, der die Bücher zum Teil verdeckt, schon fast geschlossen und verweist uns auf die Finalität des Geschehens, sozusagen den letzten Akt. Und mag auch die quadratische Form die Zeit anhalten, so ist der „Abgang" des tragischen Helden aus dem Bild die narrative Konsequenz der dargestellten Szene. Aristoteles wird die Büste loslassen, sich um die eigene Achse drehen und nach rechts aus dem Bildraum treten. Der goldenen Kette kommt in formaler Hinsicht eine wichtige Funktion zu, dient sie doch gleichsam als Indikator für die zukünftige Bewegungsrichtung.

In Rembrandts Gemälde gewahrt Aristoteles sein Scheitern in umfassender Hinsicht. Im Moment des Abschieds hebt sich alle Verblendung auf. Erst jetzt lässt sich Wichtiges von Unwichtigem trennen. Alles wird er zurücklassen müssen: Anerkennung der Mächtigen, sein Lyceum, Ruhm, Reichtum. Dabei nimmt der Maler, wie Held betont, eine eindeutige Wertung vor, wenn er die mit Goldring ausgestattete linke Hand der rechten Hand gegenübergestellt. Kein äußerlicher Erfolg hat angesichts der Katastrophe Bestand. Ja mehr noch, die Büste des Dichters erweckt den Eindruck, als würde sie ebenso mitfühlend wie traurig dem Ereignis beiwohnen. Am Ende und im Moment größten Unglücks bleibt nur der Trost des Freundes als Indiz wahrer Freundschaft, wie Aristoteles in der ${ }_{n}$ Nikomachischen Ethik" schreibt. ${ }^{51}$

\section{2. "Begrijpen“}

Doch wie steht es um die kunsttheoretische Aussage des Bildes? Liedtke hat auf die vermeintliche Vormachtstellung des Sehsinns in der aristotelischen Philosophie und den Paragone verwiesen. Dies sei im Folgenden insofern korrigiert, als Rembrandt meines Erachtens den Paragone als rhetorisches Vehikel und pseudophilosophische Debatte entlarvt. Um dies zeigen zu können, müssen wir uns jenen Überlegungen des Aristoteles zuwenden, die der Hand und dem Tastsinn gewidmet sind. ${ }^{52}$

Einen ersten Hinweis können wir dabei der holländischen Ausgabe der „Leben und Meinungen berühmter Philosophen “ aus dem Jahre 1655 entnehmen. Zwei Jahre nach Entstehung des Gemäldes war der Text des Diogenes Laertius' von Paschier de Fijne ins Niederländische übersetzt worden und 1655 in Rotterdam erschienen. Interessant ist der Titel, den der holländische Gelehrte

Vgl. Aristoteles, Nikomachische Ethik, übersetzt von Eugen Rolfes, bearbeitet von Günther Bien, Darmstadt 1995, VIII, 11, 1171a35-b13. 
seinem Buch gab: „Kort begrijp van Diogenes Laertius, zijnde het leven heerlijke Spreuken, loffelijke Dagen en snedige Antwoorden der oude philosophen, waar bijkomen eenige treffelijke Spreuken en Gelijkenissen uyt verscheyden heydensche en andere schrijvers."

Der didaktische Anspruch dieses Werks wird schon im Titel deutlich. Es geht um Sinnsprüche, ebenso prägnante wie geistreiche Formulierungen, die uns bei unserer Lebensführung beraten sollen. Entsprechend wird Diogenes Laertius' Text um weitere Dicta und Gleichnisse ergänzt, wie uns der Titel ankündigt. Aufschlussreich sind aber vor allem die ersten beiden Worte „Kort begrijp“, die uns daran erinnern, dass im Niederländischen wie im Deutschen Verstehen und Ertasten eine semantische Verwandtschaft aufweisen. Im idiomatischen Ausdruck „Begreifen“ gehören Fühlen und Verstehen zusammen. Das Tasten wird zum Erkennen. Ganz aristotelisch wird im Wort „Begriff“ die Hand zur erkenntnistheoretischen Instanz der Vermittlung des empirisch Gegebenen im Sinne eines intelligiblen Sachverhalts.

Rembrandt inszeniert in seinem Gemälde ja gleichermaßen Sehen wie Tasten. Dabei bedient sich der Künstler eines Kunstgriffs und geht durchaus augenzwinkernd vor, wenn er einen sehenden Menschen tastend und einen blinden Menschen „aufblickend“ zeigt. Auf spielerische Weise werden hier inneres und äußeres Sehen, Fühlen und Tasten miteinander in Beziehung gebracht. ${ }^{53}$

Nun stellt sich die Frage, ob Rembrandt mit den Überlegungen des Aristoteles zur Wahrnehmung vertraut war, und ob er dessen besondere Wertschätzung der menschlichen Hand kannte. Denn der griechische Philosoph kann mit Fug und Recht als Apologet der Hand gelten, der den Sinnen in „De anima“ im Unterschied zu Plato eine verlässliche und wichtige Erkenntnisfunktion zugesprochen hatte. ${ }^{54}$ So findet der Philosoph die schönen Formulierungen, dass

53 Dabei bedient sich der Künstler bei seiner Gestaltung der rhetorischen Figur des Chiasmus, sehen wir doch eine Art Crossover von Sehen und Tasten, das den innigen $\mathrm{Zu}$ sammenhang beider Sinne verdeutlicht. Zur Thematik der fünf Sinne mit besonderer Berücksichtigung der Wechselbeziehung von Tasten und Sehen vgl. Hartmut Böhme, „Der Tastsinn im Gefüge der Sinne. Anthropologische und historische Ansichten vorsprachlicher Aisthesis", in: Kunst- und Ausstellungshalle der Bundesrepublik Deutschland (Hg.), Tasten, Göttingen 1996, S. 185-210.

54 Entscheidend ist für den Philosophen das aktive Hervorrufen des Wirklichen durch die Sinne, ja mehr noch sogar des Denkbaren. So heißt es in seiner Schrift „De Anima“: „Und deshalb könnte jemand ohne Wahrnehmung nichts lernen, noch auch begreifen. Und wenn man etwas betrachtet, dann muß man es zugleich mit einem Vorstellungsbild betrachten. Die Vorstellungsbilder sind nämlich wie die Wahrnehmungsobjekte, nur ohne die Materie." Aristoteles, Über die Seele, Griechisch-Deutsch, eingeleitet, übersetzt und kommentiert von Horst Seidl, Hamburg 1995, III, 8, 432a24-29. 
die "Seele wie die Hand" und diese das „Organ der Organe" sei. ${ }^{55}$ Die Sinne sind der Mittler zwischen der objektiv gegebenen Welt und der verstandesmäßigen Erkenntnis, ohne „Wahrnehmung [lässt sich, J.M.] nichts lernen, noch [...] begreifen". 56

Ohne Zweifel ließen sich der aristotelischen Philosophie auch Passagen entnehmen, die seiner großen Wertschätzung des Sehsinns Rechnung tragen, aber in systematischer Hinsicht ist die Intelligenz des Menschen, der dynamische Zusammenhang von Erfahrung und Erkenntnis die Folge des Zusammenspiels aller Sinne. Tasten und Sehen sind für den Philosophen Schwestersinne insofern, als das Tasten eine Fortsetzung des Sehens und das Sehen eine Fortsetzung des Tastens darstellt, im Sinne einer „Zusammenarbeit“ von Nah- und Fernsinn. Dem Tastsinn kommt dabei die Aufgabe zu, den Bezug zur Wirklichkeit auf Dauer stellen zu können. Denn im Unterschied zum Sehen, das abhängig vom Licht ist, oder dem Hören, das von der Übertragung des Schalls bestimmt wird, vermag das Tasten die Kontinuität der äußeren Wirklichkeit zu vermitteln. So kommt dem Tastsinn eine außergewöhnliche Stellung zu, stellt er doch eine unhintergehbare Voraussetzung allen Erkennens dar. ${ }^{57}$ Das Berühren beziehungsweise Ertasten der Dinge ist bei Aristoteles von so hoher Relevanz, dass es die Basis für alle anderen Wahrnehmungsorgane bildet. Entsprechend heißt es, dass „ohne den Tastsinn kein Lebewesen bestehen “ könne. ${ }^{58}$

Erst dieser Exkurs zur Wertschätzung der Hand und des Tastens lässt uns angemessen weiterfragen, wenn wir nun über das Konzept des Paragone nachdenken wollen, wie es von Liedtke für die Deutung des Bildes in Anspruch genommen wurde. Offensichtlich geht es Rembrandt in seinem Gemälde um den Zusammenhang der Sinne Tasten und Sehen. Aber wie steht es mit der daran anknüpfenden Frage nach dem Verhältnis der Medien Skulptur und Malerei? Dürfen wir Liedtkes These von Rembrandts Inszenierung der Überlegenheit des Sehsinns und der Malerei zustimmen?

Um diese Frage beantworten zu können, müssen wir die Bildtradition berücksichtigen. Unter den bisherigen Deutungen haben von Einem und Held für den Aristoteles zahlreiche Vergleichsbeispiele angeführt. Ihr Ziel war es dabei, den Rembrandtschen Bildentwurf aus der Tradition des Sammlerbildnisses abzuleiten. Alle ihre Beispiele zeigen Humanisten und Sammler, die eine Büste berühren und in der dargestellten Person gleichsam einen „Wahlverwandten“

Ebd., III, 8, 432aı-2. Schon Alpers hat auf Aristoteles' Verständnis der Hand als Instrument beziehungsweise Organ der Seele verwiesen, jedoch ohne eine Quelle anzugeben. Vgl. Alpers 1989 (wie Anm. 3), S. 74.

56 Aristoteles 1995 (wie Anm. 54), III, 8, 432a24-26.

57 „Jeder beseelte Körper ist ja tastfähig, wie gesagt.“ Ebd., III, 13, 435a2o.

58 Ebd., III, 13, 435 a25 und 435 b26. 
finden - ganz so, als würde eine intime Zwiesprache mit dem durch die Skulptur repräsentierten Werk stattfinden, während gleichzeitig ein Buch auf dem Tisch liegt oder ein Text verfasst wird.

Mit der Vielzahl der von Held und von Einem angeführten Beispiele geht sicherlich eine gewisse Suggestion einher. Aber ist die Inanspruchnahme dieser Beispiele wirklich zwingend? Nein, denn alle diese Vergleiche verbleiben zu sehr im Allgemeinen. So handelt es sich bei den genannten Traditionen um Rahmenikonographien, die in Bezug auf Rembrandts Gemälde austauschbar bleiben. Lediglich Liedtke gibt einen zielführenden Hinweis, wenn er auf ein Gemälde von Giuseppe da Ribera, das den Tastsinn repräsentiert, und auf eine Allegorie der fünf Sinne von Theodor Rombouts aus dem Jahre 1632 verweist. Hier erkennt man in ausgelassener Gesellschaft einen Blinden, der Skulpturenfragmente auf dem vor ihm liegenden Tisch ertastet, womit offensichtlich der Tastsinn gemeint ist. In Bezug auf die genannten Gemälde merkt Liedtke zu Recht an, dass in solchen Allegorien die Überlegenheit des Seh- gegenüber dem Tastsinn zum Ausdruck komme: „As for the argument that painting is superior to sculpture as a form of imitation, this must have seemed to the artist, in his decision to portray Aristotle, an opportunity too good to miss. ${ }^{\text {"59 }}$

\section{Paragone als Scheinproblem}

Schon meine Beschreibung des bei Aristoteles vorgegebenen Zusammenspiels von Seh- und Tastsinn in Rembrandts Gemälde lassen Zweifel an Liedtkes Interpretation aufkommen. Deshalb müssen wir uns intensiver mit der von ihm angeführten Bildtradition auseinandersetzen, um uns ihre rhetorische Dimension vor Augen zu führen. So sei mit einer bisher übersehenen Federzeichnung aus dem Umfeld Guercinos begonnen, die in die Zeit um 1620 datiert wird (Abb. 5.4). Wir sehen einen Blinden mit Stock und Becher für Almosen, der eine weibliche Büste ertastet. ${ }^{60}$ Diese steht auf einem Postament, vor dessen Vorderseite sich ein gerahmtes Bild befindet, das zwei nackte Frauen zeigt, die ihre Scham verbergen, während ein Mann mit Turban an ihnen vorbei schreitet. Die Hände aller im Bild dargestellten Personen sind verdeckt und so wird der Unterschied zum tastenden Blinden deutlich hervorgehoben. Die Inschrift auf der Tafel in der oberen linken Bildecke gibt einen eindeutig

59 Liedtke 2004 (wie Anm. 32), S. 81.

6o Ich folge hier in weiten Teilen der Interpretation im Ausst.-Kat. Wettstreit der Künste Malerei und Skulptur von Dürer bis Daumier, hg. von Ekkhard Mai, Wallraf-Richartz-Museum, Köln, München und Wolfratshausen 2002, S. 260. 
Abb. 5.4

Guercino (Umfeld), Allegorie von der Überlegenheit der Skulptur über die Malerei, um 1620, Federzeichnung, Paris, Musée du Louvre

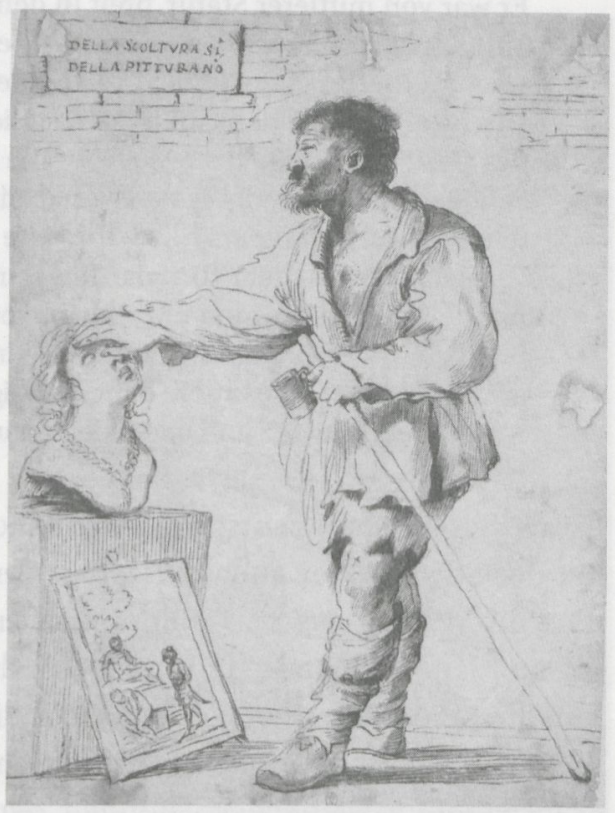

wertenden Kommentar, wenn es heißt: „DELLA SCOLTVRA SI. DELLA PITTURA NO.“, womit zugleich das eigentliche Thema im Sinne des Wettstreits von Skulptur und Malerei deutlich benannt wird.

Um jedoch die beschriebene Zeichnung angemessen verstehen zu können, muss ein geläufiger Topos der Debatte um die Überlegenheit von Malerei oder Skulptur in Erinnerung gerufen werden. In Benedetto Varchis Meinungsumfrage zum Paragone führt der Bildhauer Tribolo im Jahre 1546 aus, dass es ein Vorzug der Skulptur sei und ihre Überlegenheit zeige, wenn sie im Unterschied zur Malerei selbst von einem Blinden ertastet werden könne. Auf den ersten Blick scheint die Zeichnung, vor allem aber die Inschrift mit den Worten "SI“ und „NO“ dies bestätigen zu wollen, aber schon auf dem zweiten Blick entdecken wir einen ironischen Scherz, bleibt dem Blinden die weibliche Schönheit doch trotz intensiven Tastens verborgen. ${ }^{61}$

Dies wird umso deutlicher, wenn man erkennt, dass es sich bei dem Mann in Guercinos Zeichnung um keinen Geringeren als Michelangelo handelt. Für das Gesicht des berühmten Bildhauers konnte Guercino auf zahlreich existierende Porträtdarstellungen zurückgreifen. Aber auch Vasaris Beschreibung der äußerlichen Erscheinung Michelangelos klingt hier an. Der Biograph kommt auf Statur, Kleidung, aber auch auf Spuren der Verwahrlosung zu sprechen: 
Er war von mittlerer Statur, breit in den Schultern, doch wohlproportioniert im Verhältnis zum restlichen Körper. Als er älter wurde, trug er über Monate hinweg ununterbrochen Stiefel aus Hundefell an den nackten Beinen, sodaß ihm, wenn er sie ausziehen wollte, häufig die Haut mit abging. [...] Er hatte ein rundes Gesicht und eine viereckige, breite Stirn mit sieben geraden Furchen; seine Schläfen sprangen viel weiter vor als die Ohren, die eher groß waren und von den Wangen abstanden. [...] Seine Nase war ziemlich plattgedrückt, als Folge des Faustschlags, mit dem Torrigiani sie ihm, wie in seiner Vita berichtet, gebrochen hatte. Die Augen waren eher klein, von horngelber Farbe mit gelblichen und bläulichen Einsprengseln und mit Wimpern von spärlichem Wuchs. Er hatte schmale Lippen, die untere dabei kräftiger und etwas vorstehend. [...] Sein Haar war ebenso schwarz und mit vielen grauen Strähnen durchzogen wie sein Bart. ${ }^{62}$

Dieser Beschreibung entspricht Guercinos „Blinder“ sogar bis ins kuriose Detail der Stiefel. Aber auch der Inhalt der Allegorie ist passend, zumal wenn man an Michelangelo als militanten Vertreter der Überlegenheit der Skulptur und jenen Ausspruch des Meisters denkt, dass er unverheiratet blieb, da ihm die Kunst eine „moglie troppa“ sei, die hier in gewisser Hinsicht parodiert und ihres Pathos entkleidet wird. ${ }^{63}$ Michelangelo ist schlichtweg unfähig zur Wahrnehmung weiblicher Schönheit, denn es ist ein Privileg des Sehsinns und des Anblicks, uns verliebt zu machen, wie Leonardo einmal geschrieben hat. ${ }^{64}$ Offensichtlich soll durch diese Unfähigkeit Michelangelos die Begrenztheit des Mediums Skulptur und die Überlegenheit der Malerei sichtbar gemacht werden.

Die Zeichnung aus dem Guercino-Umkreis ist durchaus geistreich, aber keineswegs ein Einzelfall, wie entsprechende Vergleiche sichtbar machen können. So sei in diesem Zusammenhang festgestellt, dass auch in Theodor Rombouts Allegorie der fünf Sinne die Personifikation des Tastsinns an Michelangelo erinnert. Ja, bei dem Hinweis auf Michelangelo als Repräsentanten der Skulptur handelt es sich geradezu um einen Running-Gag, der immer dann zum Einsatz kommt, wenn es um die Vormachtstellung der Malerei oder den Konflikt von Malerei und Skulptur geht. Auch Gerrit van Honthorst spielt auf den italienischen Bildhauer an und lässt ihn während einer Zahnoperation zum neugierigen Zuschauer werden, wobei ihm unbemerkterweise eine Geldbörse gestohlen wird und die Haltung des Patienten ohne Zweifel an die Mittelfigur der Laokoongruppe denken lässt, bei deren Auffindung im Jahre

62 Giorgio Vasari, Das Leben des Michelangelo, neu übersetzt von Victoria Lorini, hg., kommentiert und eingeleitet von Caroline Gabbert, Berlin 2009, S. 213.

63 „Io ho moglie troppa, che è questa arte che m' ha fatto sempre tribolare“. Giorgio Vasari, Vita di Michelangelo, Anm. und Appendici von Gaetano Milanesi, Pordenone 1993, S. 127.

64 Vgl. Leonardo da Vinci, Traktat von der Malerei, hg. von Marie Herzfeld, Jena 1925, S. 21. 
Abb. 5.5

Lieven Mehus, Der Tastsinn, um 166o, Öl auf Leinwand, Privatsammlung (Italien)

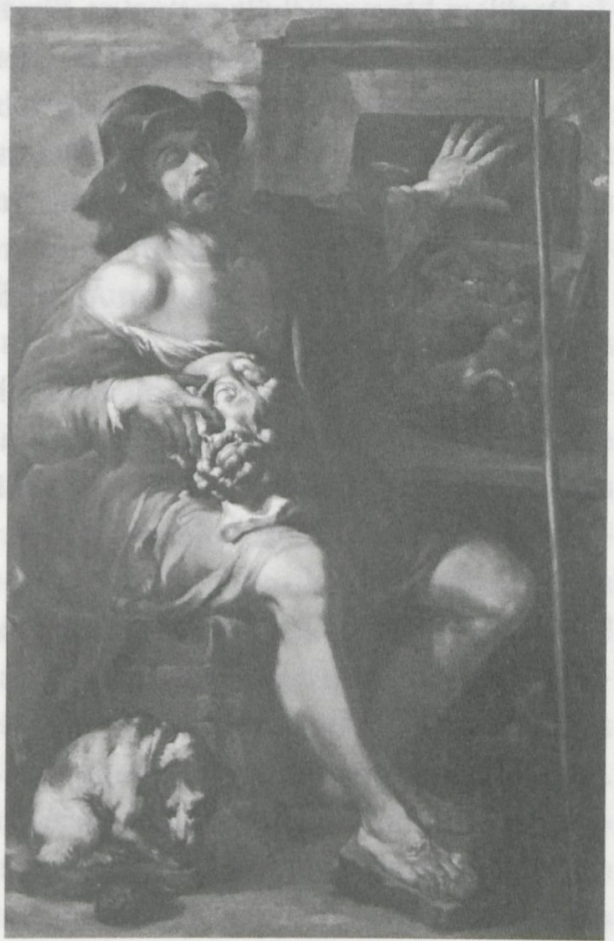

1506 der Künstler bekanntlich anwesend war. ${ }^{65}$ Oder ein weiteres Mal Rombouts, der das Kryptoporträt im Anschluss an Caravaggio mit vergleichbarer Intention wie van Honthorst zur Anschauung bringt. ${ }^{66}$

Noch extremer in Bezug auf die Abwertung des Tastsinns ist ein Gemälde von Lieven Mehus, das sich heute in italienischem Privatbesitz befindet und in die Zeit um 166o datiert wird (Abb. 5.5). Interessant ist für uns der Umstand, dass der Blinde das Gesicht einer Homer-Büste ertastet und mit seiner Linken über die Oberfläche eines Gemäldes streicht, womit einmal mehr das Argument Tribolos aufgegriffen wird. Dazu passt, dass die am Boden befindliche Schildkröte bei Cesare Ripa eine Begleiterin des Tastsinns darstellt. ${ }^{67}$ Zudem stehen die Füße des Blinden auf einem flachen Stein, der an eine Plinthe und zugleich daran erinnert, dass Skulpturen von sich aus nicht stehen, sondern ohne eine statisch-unterstützende Hilfskonstruktion umfallen würden.

65 Vgl. Jürgen Müller, „Laokoon als Simulant. Gerrit van Honthorsts ,Zahnarzt‘ in neuer Deutung", in: Hartmut Böhme und Beate Slominski (Hg.), Das Orale. Die Mundhöhle in Kulturgeschichte und Zahnmedizin, Paderborn 2013, S. 203-218, hier S. 211.

66 Theodor Rombout, Der Zahnbrecher, um 1628, Öl auf Leinwand, $125 \times 204 \mathrm{~cm}$, Münster, LWL - Landesmuseum für Kunst und Kulturgeschichte.

67 Wettstreit der Künste 2002 (wie Anm. 6o), S. 263. 
Darüber hinaus erhält man den Eindruck, dass es eine gewisse Ähnlichkeit zwischen dem Gesicht des tastenden Mannes und dem Porträt Homers gibt, die dem Blinden jedoch verborgen bleibt. Dies wird umso deutlicher, als der Blinde ja nicht nur die Büste Homers ertastet, sondern im Begriff ist, ein Bild zu berühren. Hier ist eine Kentaurenschlacht dargestellt, wie sie von dem

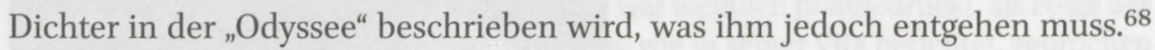
Er ist unfähig zur Erkenntnis von Ähnlichkeit, die ein Privileg vergleichenden Sehens darstellt.

Hier müssen wir einen Moment innehalten und uns in Erinnerung rufen, dass Aristoteles an der Entstehung solcher Allegorien nicht ganz unschuldig war. Im Laufe des 17. Jahrhunderts avanciert seine Philosophie in den Niederlanden zur Schulphilosophie und damit die in ihr vertretene positive Bewertung der Sinnlichkeit und des Tastens. ${ }^{69}$ Die Maler fühlen sich entsprechend herausgefordert, auf die Leistungsfähigkeit ihres Mediums im Unterschied zum Tastsinn zu insistieren, wovon die soeben vorgestellten Werke anschaulich berichten. So ließen sich zahlreiche weitere Beispiele anführen, die von der Popularität solcher Sinne- und Paragone-Allegorien Zeugnis ablegen. Aber in unserem Zusammenhang reicht es festzustellen, dass es in diesen Beispielen nur auf den ersten Blick um die Überlegenheit des Tastsinns geht, wenn mit einem tastenden Blinden Tribolos Argument aus Varchis Schrift aufgegriffen wird.

Es ist wahr, ein Blinder kann eine Skulptur ertasten, während ihm der Inhalt eines Gemäldes unzugänglich bleibt. Doch was bleibt ihm dafür alles verborgen? Genau dies machen die Bildbeispiele deutlich, dienen sie doch offensichtlich der Aufwertung der Malerei. Diese zeichnet sich durch zahlreiche Möglichkeiten aus, die der Skulptur vorenthalten bleiben: die gleichzeitige Darstellung von Ferne und Nähe, das Verliebt-Machen des Betrachters oder vergleichendes Sehen und Erkennen. Ja, es ist ein Privileg des Sehsinns und eine wesentliche Voraussetzung visueller Erkenntnis, Ähnlichkeiten zu entdecken. Das alles bleibt einem Blinden trotz seines Tastsinns unzugänglich, und so schlägt das vermeintliche Lob der Skulptur notwendig in Tadel um. Mehr noch, die Künstler machen sich über Michelangelo als den wichtigsten Repräsentanten der Skulptur lustig, weil ihm weibliche Schönheit verborgen bleibt.

Zieht man diesen Kontext für Rembrandts Gemälde hinzu, wird deutlich, dass er sich an diesem rhetorischen Spiel nicht beteiligt. Vielmehr geht es ihm

68 Vgl. Homer, Odyssee, Griechisch und Deutsch, übertragen von Anton Weiher, Düsseldorf 2007, XXI, 303.

69 Vgl. Paul Dibon, „Der Philosophieunterricht in den Niederlanden. Die Republik der Vereinigten Niederlande ${ }^{a}$, in: Jean-Pierre Schobinger (Hg.), Die Philosophie des 17. Jahrhunderts, Bd. 2/1: Frankreich und Niederlande, Basel 1993, S. 42-70. 
darum, den Paragone als Scheinproblem zu entlarven. Dies wird insofern offenbar, als Tasten und Sehen in keinem ausschließenden, sondern in einem verbindenden Verhältnis stehen. So gilt es zunächst die Verkehrung des etablierten Paragone-Motivs zu betonen, wenn der Sehende tastet. Zudem gibt Rembrandt dem Betrachter in Bezug auf seine Darstellung des Aristoteles einen verborgenen Hinweis, wenn man dessen Haltungsmotiv genauer betrachtet, das aus signifikanten Vorbildern zusammengesetzt ist. ${ }^{70}$

Für den ausgestreckten rechten Arm nutzt er das Vorbild des Aristoteles aus Raffaels Schule von Athen, wie es ihm aus Giorgio Ghisis Nachstich bekannt gewesen sein dürfte. Freilich dreht er die Figur um $45 \mathrm{Grad}$ nach rechts. Auch die Dreiviertelansicht des leicht nach links gewendeten Kopfes entnimmt er dem genannten Vorbild. Für den linken an die Hüfte geführten Arm greift er zudem auf Raffaels Darstellung des Homer im Parnass zurück. So treffen sich in Rembrandts Gemälde nicht nur Homer und Aristoteles in Form der Büste und des tastenden Mannes, sondern schon in der Darstellung des Philosophen findet eine Synthese zweier Raffaelmotive statt, die auf beide Denker verweist. In Rembrandts Gemälde ist es, als würden sich zwei alte Freunde verabschieden. Traurig blickt der Dichter auf den Philosophen. In Wehmut lässt Aristoteles seine Welt vor dem inneren Auge Revue passieren. Dabei vermittelt sich alles durch die auf dem Kopf ruhende und fühlende Hand. Frei nach Aristoteles kommt ihr wie der Seele eine vermittelnde Funktion zu. Sie ist in jeder Hinsicht das Zentrum des gesamten Bildes.

Was Ruffo an Rembrandts Gemälde schätzte, wissen wir nicht. Das Pathos eines existenziellen Moments? Die ebenso kühne wie dramatische Lichtgestaltung? In jedem Fall gab er zwei weitere Werke in Auftrag. ${ }^{71}$ So kann man durchaus fragen, in welcher Form der Künstler glaubte, sein Gemälde durch diese Bilder ergänzen zu können. Eines der beiden Gemälde zeigt den diktierenden Homer, wie er in der hellenistischen Büste dargestellt wird. Allerdings ist das Bild nicht mehr vollständig überliefert, sondern wurde durch einen Brand in Teilen zerstört. Lediglich durch die Vorzeichnung wissen wir um die Gesamtanlage des Gemäldes. Stellt man sich dieses Bild in Bezug zum Aristoteles-Gemälde vor, überführt und transformiert Rembrandt damit Skulptur in Malerei und Stein in Fleisch. Aus der Büste wird der leibhaftige Dichter. Und mit dem Bildnis des diktierenden Homer werden dem Sehen und Tasten des Aristoteles-Gemäldes das Sprechen, Hören und Schreiben hinzugefügt.

70 In seiner Biographie des Stagiriten überliefert Diogenes Laertius (Laertius 1990, wie Anm. $38, \mathrm{~V}, 1,20$ ) das schöne Dictum, dass Freundschaft eine Seele in zwei Körpern sei.

71 Siehe exemplarisch Schwartz 2006 (wie Anm. 4), S. 218 und Rousseau 1962 (wie Anm. 4), S. 15 off. 
Abermals ist es die Hand eines jungen Schreibers, die fähig ist zur Vermittlung und das gesprochene Wort in Schrift transformiert.

Doch auch der Darstellung Alexanders muss im Kontext des Aristotelesund Homer-Gemäldes Beachtung geschenkt werden. Lange ist angenommen worden, dass das heute in Glasgow hängende Gemälde Der Mann in Rüstung Alexander als jugendlichen Helden mit Schild und Lanze repräsentiert und sich in Ruffos Besitz befunden hätte. ${ }^{72}$ Doch wurde in der Forschung darauf hingewiesen, dass Alexander im Rechnungsbuch des sizilianischen Kunstliebhabers als sitzend beschrieben wird, was augenscheinlich nicht mit dem genannten Gemälde übereinstimmt. ${ }^{73}$ Indes ist eine quadratische Federzeichnung Rembrandts überliefert, die als Vorskizze für Ruffos Gemälde gedient haben könnte (Abb. 5.6). Der Leidener Künstler hat einen jungen Mann sitzend und mit aufgelehntem Arm wiedergegeben, der sinnend nach unten schaut. Daneben betrachtet ein zweiter Mann grübelnd eine Büste, die auf einem Tisch steht. Rembrandt hat auf dem Blatt neben der Zeichnung die Kopfstudie eines behelmten Mannes hinzugefügt, die abermals an die Darstellung Alexanders erinnert. Als sicher kann gelten, dass Thema und Bildformat dem Aristoteles-Gemälde entsprechen, welche Schlüsse man auch immer daraus ziehen will. ${ }^{74}$ Da Ruffos Gemälde des Alexander jedoch verschollen ist, muss es bei Hypothesen bleiben. ${ }^{75}$

Wenn man auch heute noch etwas aus dem New Yorker Bild lernen kann, dann ist es wohl jene Einsicht in die Fragilität des Glücks, von der Aristoteles in der "Nikomachischen Ethik" spricht. ${ }^{76}$ So repräsentiert Rembrandts Darstellung des Philosophen das Ende jenes fragilen Gleichgewichts von Tugend, Gesundheit und Besitz, das der Stagirit als Eudämonie bezeichnet. ${ }^{77}$ Auch der

72 Dabei bezieht sich der Maler insofern auf sein Aristoteles-Gemälde, als die heldenhafte Darstellung Alexanders im Medaillon der Ehrenkette ihren Ausgangspunkt nimmt.

73 Vgl. Bikker 2014 (wie Anm. 9), S. 278, Anm. 27. Allerdings hat schon Christian Tümpel in seiner Rezension zu „Rembrandt 1606/2006. New Rembrandt Documents“ auf die Beschreibung des verlorenen Gemäldes hingewiesen und dass es sich daher bei der Glasgower Version eben nicht um das ehemalige Gemälde Ruffos handeln kann. Vgl. Christian Tümpel, „Rez.: Rembrandt 1606/2006“, in: sehepunkte, 2008, Nr. 7/8, http://www.sehe punkte.de/2008/07/12146.html (zuletzt abgerufen am 12. Oktober 2016).

74 Bikker schreibt gar: „Falls der heute verlorene Alexander, den Rembrandt an Ruffo ${ }_{1661}$ lieferte, in einem ähnlich kontemplativen Geist geschaffen wurde, hätte der Auftrag in seiner Gesamtheit eine Trilogie schöpferischer Melancholie umfasst." Bikker 2014 (wie Anm. 9), S. 227.

75 Vgl. ebd., S. 224.

76 Vgl. Aristoteles 1995 (wie Anm. 51), I, 11, 1100a-1101a.

77 Besitz, Schönheit und äußere Anerkennung sind keinesfalls gering zu schätzen, sie sind vielmehr notwendig und Teil einer um Ausgleich bemühten Lebensführung. Vgl. ebd., I, 9, 1098b3o-1099b5. 
Abb. 5.6

Rembrandt, Nachdenklicher Mann am Tisch sitzend, o.J. Zeichnung, Paris, Fondation Custodia

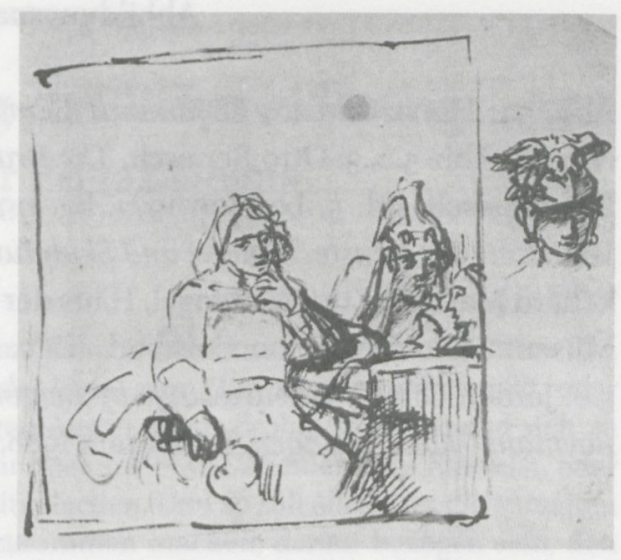

Weise entgeht dem Scheitern nicht. ${ }^{78}$ Aber wichtiger als diese existentielle Erkenntnis und die damit verbundene Selbstbescheidung erscheint mir jene der Aufhebung der Gegensätze und des Eigennutzes zugunsten der Freundschaft. Der griechische Philosoph schreibt in der "Nikomachischen Ethik“ über die edelste der drei Arten von Freundschaft: „Diese Freundschaft also ist hinsichtlich der Zeit und der übrigen Bedingungen vollkommen; in ihr wird jedem seitens des anderen in allem dasselbe und das gleiche zuteil, wie es bei Freunden sein muß. ${ }^{479}$ So wie sich im Aristoteles-Gemälde Tast- und Sehsinn ergänzen, so stehen auch die Künste in einem freundschaftlichen Verhältnis zueinander. Dabei kann keine Kunst von sich behaupten, edler als eine andere zu sein. ${ }^{80}$ Was lehrt uns das alles? Das Schicksal vermag niemand aufzuhalten. Den Verlust von Reichtum und Anerkennung kann Kunst nicht kompensieren, den Tod nicht abwenden. Aber wie die Freundschaft ist sie ein hohes Gut. Noch in der Darstellung des Scheiterns vermittelt sie Trost und Empathie. Ein anhaltendes Gespräch über Jahrhunderte hinweg.

Hier sei die Charakterisierung des Aristoteles bei Diogenes Laertius und die dort gegebene Definition menschlichen Glücks hinzugezogen: „Als alleiniges Endziel stellte er die Ausübung der Tugend in einem vollkommenen Leben hin. Die Glückseligkeit erklärte er für einen durchgängigen Zusammenschluss von dreierlei Gütern: von seelischen, die er auch als die ersten dem Range nach bezeichnet, zweitens von körperlichen Gütern, also von Gesundheit, Ruhm und was dem ähnlich. Die Tugend für sich, meinte er, sei nicht hinreichend zur Glückseligkeit, sie bedürfe auch der körperlichen und äußerlichen Vorzüge, denn der Weise würde ein unglückseliges Dasein führen, sei es nun, daß er in qualvollen Leiden oder in Armut oder in ähnlichen Umständen lebt." Laertius 1990 (wie Anm. $38), \mathrm{V}, 30$.

79 Aristoteles 1995 (wie Anm. 51), VIII, 5, 1156b33-35.

8o Dies stellt ein implizites Argument gegen Junius dar, der in seiner Antikenbegeisterung die Skulptur favorisiert. Siehe dazu auch Müller 2015 (wie Anm. 46), S. 289. 


\section{Abbildungsnachweis}

Abb. 5.1: Horst Gerson, Rembrandt Gemälde, Gesamtwerk, Wiesbaden 1968, Nr. 286; Abb. 5.2, 3: Otto Benesch, The Drawings of Rembrandt, 6 Bde., hg. von Eva Benesch, Bd. 5, London 1973, fig. 119o; fig. 1096; Abb. 5.4, 5: Ausst.-Kat. Wettstreit der Künste. Malerei und Skulptur von Dürer bis Daumier, hg. von Ekkehard Mai und Kurt Wettengel, Haus der Kunst, München, Wallfraf-RichartzMuseum und Fondation Corboud, Köln, München 2002, Nr. 61, Nr. 64; Abb. 5.6: Jeroen Giltaij, The drawings by Rembrandt and his school in the Museum Boymans-van Beuningen, Rotterdam 1988, Nr. 180, fig. a 